DOI: 10.28995/2227-6165-2017-27-3-60-66

\title{
О.В. Калугина
}

доктор искусствоведения, главный научный сотрудник кафедры кино и современного искусства РГГУ evaksenia@gmail.com

\section{АВГУСТЕЙШИЕ ЗАКАЗЧИКИ СТАНКОВОЙ ПЛАСТИКИ В РОССИИ ВТОРОЙ ПОЛОВИНЫ ХІХ - НАЧАЛА ХХ ВЕКА}

Статья посвящена мало разработанной проблеме определения круга станковых произведений русских скульпторов, выполненных по заказу царствующего дома Российской империи во второй половины XIX - начале $\mathrm{XX}$ веков. Данная проблема тесно переплетена с вопросами коллекционирования представителями императорской фамилии русской и европейской пластики. В данной публикации представлен только начальный этап исследования. Вкусы семьи Романовых не только стимулировали создание произведений определенной стилистической направленности и жанра, но и в дальнейшем предопределили состав собраний скульптуры крупнейших государственных музейных собраний - Государственного Эрмитажа и Государственного русского музея.

\footnotetext{
Ключевые слова: русская станковая пластика, императорский заказ, коллекционирование, собирательство
}

\begin{abstract}
Article is devoted to a little developed problem of definition of a circle of easel works of the Russian sculptors custom-made the reigning house of the Russian Empire in the second half of XIX-of the beginning of the 2oth century. This problem is closely bound with collecting questions representatives of an imperial surname of the Russian and European plasticity. Only the initial stage of a research is presented in this publication. Tastes of a family of Romanov not only stimulated creation of works of a certain stylistic orientation and genre, but also further have predetermined structure of meetings of a sculpture of the largest state museum meetings - the State Hermitage and the State Russian Museum.
\end{abstract}

Keywords: Russian easel plasticity, imperial order, collecting

Особенности предмета, которому посвящена данная публикация, заключается в том, что до недавнего времени он практически не мог привлекать к себе внимание. С одной стороны, в советскую эпоху такая постановка вопроса вообще не воспринималась как легитимная. С другой, только 40о-летие дома Романовых активизировало интерес к данной стороне вопроса, очевидно, по инерции почти не проявляемый в постсоветские четверть века. Конечно, немалое значение имеет тот факт, что последние десятилетия вообще проходят под знаком повышенного интереса к истории коллекционирования и собирательства. И это вполне объяснимо, так как количество коллекционеров резко возросло, и множество искусствоведов оказываются так или иначе вовлеченными в соответствующую сферу бытования предметов искусства. Естественно, сразу активизировался интерес и к тому, «как это было раньше», проще говоря, к истории вопроса.

Из всего сказанного выше ясно, что собирать материал по предмету приходится по крупицам, извлекая его из каталогов и писем, воспоминаний и критических обзоров. Таким образом, эта публикация может расцениваться только как начало исследования, в котором представлен лишь самый ранний этап реконструкции и анализа материала. Тем не менее, определенные позиции необходимо оговорить сразу. Выстраивая круг памятников, которые можно отнести к произведениям, выполненным по заказам царствующего дома, необходимо отдавать себе отчет, насколько мало на сегодняшний день мы представляем себе объективную характеристику этого

* Исследование выполнено при поддержке РГНФ (РФФИ) грант а16-4-00322 


\section{O.V. Kalugina August customers of easel plastics \\ in Russia in the second half of XIX-early XX century}

явления. Например, можно толковать ситуацию крайне расширительно, если принять во внимание, что с середины XIX века Императорская академия художеств была переподчинена Министерству императорского двора и уделов, то есть ведомству, подконтрольному только правящей династии, а не Сенату. Недаром президентами ИАХ с 1843 года становились только представители августейшей фамилии. В таком контексте все работы, выполненные по заказу самой Академии можно считать заказами Двора, то есть заказами Романовых.

Однако гораздо важнее, по нашему мнению, провести более тщательные и детальные изыскания, а именно, попытаться установить, какие конкретные произведения заказывались определенными членами августейшей фамилии. Первые усилия в этом направлении дали на сегодня определенный результат, и можно смело утверждать, что скульптуру представители династии заказывали часто, коллекционировали охотно, многие представители семьи Романовых очень неплохо в ней разбирались и высоко оценивали скульптурное дарование как таковое.

Заметим, что данное положение достаточно важно, поскольку наше исследование посвящено прежде всего второй половине XIX века, то есть времени для русского ваяния очень непростому. Монументальная скульптура переживает очевидный кризис, и, несмотря на большое количество проводимых конкурсов, удачные решения находились лишь в результате длительных усилий, а в некоторых случаях, как, например, с памятником Александру II в Петербурге, эти старания так и не увенчивались успехом [Калугина, 2015]. В эпоху историзма скульптуре выживать было действительно нелегко. От нее требовали «правды жизни», хотя до сих пор не вполне понятно, что именно под этим подразумевалось и зачем правда жизни нужна искусству, заведомо ее копией не являющемуся. Академическая школа планомерно третировалась В.В. Стасовым, но никакой альтернативы ей во второй половине XIX столетия еще не существовало, так как скульптурный класс Московского училища живописи и ваяния находился в стадии становления. Как результат, превозносились сомнительные достижения так называемых автодидактов, активно поддерживался литературоцентризм, столь губительный для обобщенного языка ваяния.

Тем не менее, дворцовые интерьеры по-прежнему украшались коллекциями скульптур, начало которым было положено, как хорошо известно, еще в Петровскую эпоху. Высочайший расцвет отечественной пластики конца XVIII - первой трети XIX веков закономерно закрепил эту традицию, и было бы совершенно невозможно себе представить, что она, просуществовав полтора столетия, вдруг иссякла бы за какие-то тридцать лет на фоне расцвета заказов царствующей династии на монументальную скульптуру [Калугина, 2013, с. 104-130]. Естественно, такого и не случилось, тем более, что интерьеры эпохи историзма продолжали активно обращаться к стилистике тех периодов истории искусства, когда пластика занимала одно из ведущих мест в художественной культуре. В программах выпускных работ архитекторов той поры мы найдем установки на выполнение работ, условно говоря, в стиле «нео-грек», «ренессанс», «помпеянском» и т.д., что как бы заведомо предопределяло не только уместность, но и необходимость присутствия произведений ваяния в соответствующим образом оформленном пространстве.

Одновременно в период активного внедрения в жизнь теории официальной народности и в рамках стимулируемого ею сложения национально-романтического направления в искусстве на арену вышел русско-византийский, а позднее - неорусский стили. Тематика соответствующей направленности, естественно, активно поддерживалась академическими программами, в том числе по скульптуре, наряду с античными и библейскими сюжетами. Также огромную роль в формировании художественного вкуса и эстетических норм в сфере ваяния этого периода играли, как уже неоднократно отмечалось нами в ранее опубликованных работах, такие грандиозные проекты середины XIX столетия, как возведение Исаакиевского собора и храма Христа Спасителя в Петербурге и Москве соответственно. Несомненно, монументальная пластика этих ансамблей формировала определенную стилистическую программу и для станковых композиций.

Таким образом, время способствовало свободе заказчика в выборе стилистической ориентации произведений, их разнообразной содержательной интерпретации и манеры конкретного 


\section{О.В. Калугина Августейшие заказчики станковой пластики}

в России второй половины XIX - начала XX века

исполнителя. Заметим, что на сегодняшний день крайне сложно определить, в каких случаях представители царствующего дома являлись заказчиками в прямом смысле этого слова. Участие в появлении того или иного станкового скульптурного произведения могло выражаться очень разнообразно. Данный материал еще только должен стать предметом самого тщательного анализа, пока же мы видим нашу задачу в привлечении внимания специалистов к этой проблеме. Поскольку на протяжении очень долгого времени музейных сотрудников и искусствоведов вообще не интересовал вопрос о роли августейшего заказчика в формировании собраний скульптур, то теперь поле деятельности в этом направлении открылось просто необозримое.

Так, богатая скульптурная коллекция, сформированная супругой будущего императора Николая I Александрой Федоровной, украшала интерьеры Аничкова дворца еще в середине девятнадцатого столетия. О сохранении интереса к собиранию скульптур говорит и «Опись скульптурным предметам, находящимся на половине покойного Императора Николая I и Императрицы Александры Федоровны в Николаевском дворце», составленная во второй половине 1850-х годов [Карпова, 2009, с. 272]. Перемещенные позднее в Зимний и Таврический Дворцы, эти произведения, во всяком случае те, которые сохранились, в дальнейшем пополняли собрание Русского музея. Заметим, что прослеживание заказов императорской фамилии тесно увязано с темой собирательства и коллекционирования, так как оба эти процесса характеризовали вкусы представителей царствующего дома.

Что же собирали великие князья, а затем и государи? Достаточно большую часть коллекции составляли произведения русских и зарубежных скульпторов конца XVIII - первой половины XIX века, в том числе портреты членов императорской фамилии и родственников императрицы по линии прусского королевского дома. Но приобретались, скорее всего, а также заказывались в качестве авторских копий или переведенных в твердый материал оригиналов, работы и современных мастеров. Е.В. Карпова упоминает небольшие бронзовые скулыптуры И.Ф. Ковшенкова военной и исторической тематики, отлитые по специальному распоряжению государя [Карпова, 2009, с. 274]. Заказы мастеру продолжал делать и Александр II, его работы «Дак X века» (1861), «Скиф-князь» (1862), «Сармат» (1863) и другие проходят по описям пластических произведений Аничкова дворца, в том числе кабинета Александра III.

Большой симпатией со стороны императорской фамилии пользовались работы Н.И. Либериха, причем не только относящиеся к новой разновидности станковой скульптуры, а именно кабинетной пластике, такие как «Охота на волка», «Бегущий северный олень» и другие. Но приобретались и специально заказываемые большие работы, например, на тему императорской охоты на медведя (1865-1866) или отлитая в бронзу по высочайшему заказу «Раненная Ахилессом царица амазонок Пенфесилия» (1852). В кабинете цесаревны располагалась мраморная статуя «Татьяна» П.П. Забелло (1869), выполненная скульптором в Италии, о которой нет данных как о заказной работе. Однако этот же скульптор выполнял статую для фонтана «Наяда» действительно по заказу императрицы Александры Федоровны. Из Аничкова дворца в Русский музей был перемещен и мраморный рельеф Н.А. Лаверецкого «Амур у дверей Психеи» (1885), украшавший один из каминов в парадных покоях, а в 1920-х годах в Музей истории города была передана статуя Петра I работы А.М. Опекушина.

Здесь же хранилась бронзовая статуя М.М. Антокольского «Христос перед судом народа» (1874, отлив 1878), отлив которой выполнялся по заказу цесаревича, то есть будущего Александра III [Кривдина, 2006, с. 250]. Заметим, что в 1871 году Антокольский получил официальный заказ государя, переданный через конференц-секретаря Академии П.Ф. Исеева, на перевод в мрамор статуи «Царь Иван Васильевич Грозный» за гонорар в 10000 рублей [Кривдина, 2008, с. 57]. Но по рекомендации Совета академии она была отлита из бронзы и приобретена Александром II именно в таком виде. Как видно из приведенного материала, еще достаточно трудно бывает разграничить работы, созданные по прямому заказу императорской семьи, и произведения, просто приобретаемые ею для своих коллекций. Уточнение этого вопроса, несомненно, потребует проведения дополнительных исследований. 


\section{O.V. Kalugina August customers of easel plastics \\ in Russia in the second half of XIX-early XX century}

Выдающиеся произведения русской скульптуры второй половины XIX века находились в коллекции герцога Максимилиана Лейхтенбергского и великой княгини Марии Николаевны в Сергиевке под Петергофом. Супруг старшей дочери Николая I стал, как известно, первым президентом Императорской академии художеств из числа представителей августейшего семейства. После смерти герцога в 1852 году его сменила вдова - страстная поклонница искусства. К сожалению, драматические события нашей истории, и прежде всего - фашистская оккупация мало что оставили от коллекции дворца, включавшей в себя даже произведения античных мастеров. Большой интерес в контексте нашей темы представляют сведения о приобретении Марией Николаевной для парка Сергиевки бронзового отлива статуи работы И.И. Подозерова «Терм, древний языческий бог, охраняющий границы полей» (1857) [Кривдина, 2008, с. 300]. Как видим, вкусы и этой ветви Романовых сохраняли свою классицистическую ориентацию.

Несомненно, одно из центральных мест не только в коллекции дворца в Сергиевке, но и в истории русского искусства середины XIX века в целом, занимала статуя «Венера, снимающая сандалию» И.П. Витали, выполненная скульптором на склоне лет в 1852 году и переведенная им собственноручно в мрамор в 1853 по заказу императора. Согласно данным, приводимым Н.А. Рамазановым [Рамазанов, 1863, с. 18], именно Николай I предложил образец для своего заказа бронзовую (по уточнению Е.В. Карповой [Карпова, 2009, с. 132]) статуэтку из богатой коллекции Аничкова дворца. Для перевода в мрамор мастером был специально переработан гипсовый оригинал [Карпова, 2009, с. 169]. Одна из копий статуи была установлена перед Ольгиным павильоном на Ольгином острове в Петергофе, другая - отправлена императором в дар дочери королеве Вюртембергской в Штутгарт. Согласно данным, приводимым О.А. Кривдиной, «по заказу Николая I Витали вылепил в “pendant" статуе «Венеры» эскиз женской фигуры, о местонахождении которого в настоящее время ничего не известно» [Кривдина, 2008, с. 170].

Изысканный вкус и высшее мастерство не исчерпывают достоинств этой работы. Подлинное искусство скульптуры достаточно трудно переводимо в литературные выражения - в них исчезает то, что зритель воспринимает «кожей», то есть в полном смысле этого слова - через комплекс тактильно-кинестетических ощущений. Совершенно особый ритм внутреннего движения, основу которого задают изысканные складки драпировки, накинутой на опору, связывает воедино все детали статуи, все импульсы и напряжения ее позы и жестов. Покойная левая рука и трепетно напряженная правая, величественный поворот головы, не удостаивающей внимания бытовые подробности развязывания (или нет? Согласно Рамазанову, она обувается!) сандалии, неизбежный изгиб торса и совершенная осанка богини, которая не может быть «обытовлена» никаким занятием - все это складывается в завораживающее зрителя изысканное зрелище, не имеющее ни начала, ни конца, вечно длящееся во времени и пространстве, вечно новое и незыблемое.

Этой статуей были захвачены современники, она была безвинно обругана Стасовым [Стасов, 1952, с. 479], на пороге века XX вновь воспета Н.Н. Врангелем [Врангель, 1913], о ней, с трудом борясь с ее очарованием, сдержанно писали всё прошлое столетие. Но невозможно было изменить в ней главное - с удивительным пафосом раскрытый Витали тот факт, что в художественном воображении подлинного мастера классика как основа творческого начала скульптора всегда молода, жизненна, убедительна и неисчерпаема в своих возможностях.

Большим вниманием со стороны августейших заказчиков пользовались произведения Ф.Ф. Каменского. Выполненную под руководством Н.С. Пименова статую «Молодой скульптор» (1861) по высочайшему повелению Каменскому поручили перевести в мрамор, после чего она и была приобретена в императорскую коллекцию. Также было заказано Александром II в мраморе произведение уже зрелого мастера «Мать, учащая своего ребенка ходить», более известная как «Первый шаг» (1870). С этой целью художник отбыл на три года в Италию.

Как уже становится ясно из приведенного материала, количество заказов императорской фамилии русским скульпторам второй половины XIX века было достаточно велико, а вкусы заказчиков отличались разнообразием. В настоящее время произведения скульптуры, 


\section{О.В. Калугина Августейшие заказчики станковой пластики}

в России второй половины XIX - начала XX века

приобретенные или заказанные семьей Романовых в этот период, входят в собрание крупнейших музеев страны, а именно Государственного Эрмитажа и Государственного Русского музея. Эрмитаж пополнялся непосредственно под контролем государя, за что и именовался Императорским, и тот факт, что в 1850 годы Николай I направляет усилия на превращение его в публичный музей, ничего в этом вопросе не меняет. Так что скульптуры второй половины XIX - начала XX веков, находящиеся в собрании Эрмитажа или переданные в другие музейные коллекции, являются прямыми свидетельствами вкусов и художественных предпочтений царствующей семьи.

Практически то же можно сказать и о формировании коллекции Русского музея Александра III, ныне Государственного Русского музея. Хорошо известно, что император, еще будучи наследником престола, проявил себя как страстный коллекционер и в этом смысле подлинный сын своего времени. К концу 1880-х годов собранные им сокровища превратили Гатчинский, Аничков, Зимний и другие дворцы в настоящие склады раритетов и памятников современного искусства. Именно эти произведения сформируют первоначальные фонды музея, то есть и в данном случае мы имеем дело с непосредственным свидетельством интересов и предпочтений правящей династии и конкретно императора Александра III. Так, вывоз произведений из Аничкова дворца в избранный в качестве будущего музея Михайловский производился еще при жизни императора, то есть идея создания в столице музея национального искусства не только существовала в проекте, но и претворялась на практике.

Другим источником пополнения коллекций музея стали фонды Императорской академии художеств. Интересно, что «предлагаемые к передаче из Академии художеств произведения скульптуры рассматривались Великим князем Георгием Михайловичем. Он “изволили выразить согласие на принятие и помещение” скульптурных работ в залах Музея» [Кривдина, 2006, с. 572]. То есть данный источник пополнения также находился, но теперь уже под двойным августейшим контролем - президента Академии великого князя Владимира Александровича и принимающего члена комиссии - также великого князя.

Исследователь истории русской академической пластики О.А. Кривдина в этой связи подчеркивает: «Члены комиссии, отбиравшей произведения скульптуры для русского музея, следовали определенной системе, в основе которой были свои представления о иерархии ценностей, строгая регламентированность и отбор. Все перечисленные факторы четко соответствовали установившемуся признанию значимости мастеров и художественному уровню их работ» [Кривдина, 2006, с. 571]. В данном случае, хотя в перечне и превалируют произведения первой половины XIX века, но их отбор осуществлялся в 1897-98 годы и свидетельствовал о вкусах именно этого времени, как легко понять, во многом остававшихся неизменными. Это были по большей части скульптуры, приобретенные Академией у своих выпускников, и часто позднее, по заказу императора или членов его семьи, переведенные в твердый материал: «Ряд поступивших из Академии художеств гипсовых работ был впоследствии заменен на их мраморные варианты или бронзовые отливы: С.И. Иванов “Мальчик в бане”, Н.С. Пименов “Мальчик, просящий милостыню”, Ф.Ф. Каменский “Портрет Ф.А. Бруни”» [Кривдина, 2006, с. 572], то есть подлинные шедевры, составившие славу отечественного ваяния.

Обширность материала и необходимость еготщательного анализапока непозволяют расширить круг примеров и за пределами внимания остается еще огромное количество работ, приобретенных представителями царствующего дома, в том числе и в результате прямого заказа. Однако представленный материал позволяет подвести некоторые итоги. Можно утверждать, что развитие русской станковой скульптуры, в том числе и второй половины XIX века, находилось под пристальным вниманием августейшей семьи. Как результат, вкусы венценосных заказчиков оказывали многоуровневое воздействие на эволюцию отечественного ваяния. С одной стороны, президентство Академии художеств, осуществляемое представителями династии, предполагало уже в процессе обучения формирование тенденции в выборе образцов, определения предпочтений стилистической направленности, сложения норм и правил. Это обусловило и тот факт, что 


\section{O.V. Kalugina August customers of easel plastics \\ in Russia in the second half of XIX-early XX century}

выставляемые на академических выставках работы воспринимались позитивно и оказывались востребованными заказчиками из царствующего дома. В свою очередь это закрепляло мотивацию художника на работу в заданном направлении. О стилистической направленности этих работ мы кратко сказали ранее, но данный вопрос, конечно, заслуживает особого внимания со стороны будущих исследователей.

Одновременно внимания удостаивались и работы автодидактов, каковым в определённом смысле являлся, например, Е.А. Лансере и отчасти Н.И. Либерих, если их работы соответствовали тематическим интересам заказчика. Большим стимулом для развития скульптуры малых форм было появление интереса к новому направлению - кабинетной пластике, а также выполнение подарочных работ из драгоценных металлов и поделочных камней.

Круг мастеров, отмеченных высочайшим вниманием, который был только намечен в данной работе и на самом деле гораздо более широк, тем не менее приобрел четкие очертания, как и стилистические особенности приобретаемых или заказываемых произведений. Их авторы удостаивались наград, имели возможность работать за границей, продвигались по службе, стабильно преподавали в Академии, практически воспроизводя творческий опыт, приведший их самих к признанию. Конфликты, если и возникали, то происходили, разумеется, не между заказчиками и исполнителями, что было просто невозможно, а между исполнителем и Академией, как это произошло с Каменским, из-за недостаточного, по мнению ваятеля, признания его заслуг. Несомненно, таким образом обеспечивалась преемственность установок в подготовке скульпторов и, в определенной мере, вкусов императорской фамилии. Насколько были взаимосвязаны эти процессы, как и масштабы означенного взаимовлияния, надеемся, будет выясняться в процессе дальнейших детальных исследований.

\section{источники}

1. Врангель Н.Н. История скульптуры // История русского искусства в 6 томах. Т. 5. - Москва: І. Кнебель, 1913.

2. Карпова Е.В. Русская и западноевропейская скульптура XVIII - начала XX века. Новые Материалы. Находки. Атрибуции.

- Санкт-Петербург: Искусство-СПБ, 2009.

3. Стасов В.В. Двадцать пять лет русского искусства. Наша скульптура // Стасов В.В. Собр. соч. в 3 томах. Т. 2. - Москва: Искусство, 1952.

\section{ЛИТЕРАТУРА}

1. Калугина О.В.Памятники Александру II 1910-хгодов. К проблеметипового монумента // Русскоеискусство Нового времени. Исследования и материалы. Сборник статей Вып. 16, 2015. - С. 189-197.

2. Калугина О.В. Русская скульптура Серебряного века: путешествие из Петербурга в Москву. - Москва: БуксМАрт, 2013.

3. Кривдина О.А. Ваятели и их судьбы. Научная реконструкция творческих биографий российских скульпторов середины и второй половины XIX века. - Санкт-Петербург: Сударыня, 2006.

4. Кривдина О.А. Марк Матвеевич Антокольский. От России - до России. - Санкт-Петербург: Сударыня, 2008.

5. Рамазанов Н.A. Материалы для истории художеств в России. Кн. I. - Москва, 1863.

\section{SOURCES}

1. Karpova E.V. Russkaja i zapadnoevropejskaja skul'ptura XVIII-nachala XX veka. Novye Materialy. Nahodki. Atribucii [Russian and West European sculpture of the XVIII-early XX century. New Materials. Finds. Attributions]. Saint-Petersburg, IskusstvoSPB, 2009.

2. Stasov V.V. Dvadcat' pjat' let russkogo iskusstva. Nasha skul'ptura [Twenty-five years of Russian art. Our Sculpture] In: Stasov V.V. Sobr. Coch. V 3 tomah. Tom 2 [Stasov V.V. Coll. op. In 3 vol. Vol 2]. Moscow, Iskusstvo, 1952.

3. Vrangel` N.N. Istoriya skul ’ptury `[History of sculpture] In: Istorija russkogo iskusstva $v 6$ tomah [The history of Russian art in 6 volumes.]. Vol. 5, Moscow, I. Knebel, 1913. 


\section{REFERENCES}

1. Kalugina O.V. Pamjatniki Aleksandru II 1910-h godov. K probleme tipovogo monumenta [Monuments to Alexander II of the 1910 . To the problem of a typical monument] In: Russkoe iskusstvo Novogo vremeni. Issledovanija i materialy. Sbornik statej, vyp. 16 [Russian art of modern times. Research and materials. Digest of articles, issue 16]. Moscow, 2015. Pp. 189-197.

2. Kalugina O.V. Russkaja skul'ptura Serebrjanogo veka: puteshestvie iz Peterburga v Moskvu [Russian sculpture of the Silver Age: a journey from St. Petersburg to Moscow]. Moscow, BuksMArt, 2013.

3. Krivdina O.A. Mark Matveevich Antokol'skij. Ot Rossii - do Rossii [Mark Matveyevich Antokolsky. From Russia to Russia]. SaintPetersburg, Sudarynja, 2008.

4. Krivdina O.A. Vajateli i ih sud'by. Nauchnaja rekonstrukcija tvorcheskih biografij rossijskih skul'ptorov serediny ivtorojpoloviny $X I X$ veka [Scavengers and their destinies. Scientific reconstruction of creative biographies of Russian sculptors of the middle and second half of the XIX century]. Saint-Petersburg, Sudarynja, 2006.

5. Ramazanov N.A. Materialy dlja istorii hudozhestvv Rossii.Kniga 1 [Materials for the history of arts in Russia. Book 1]. Moscow, 1863. 